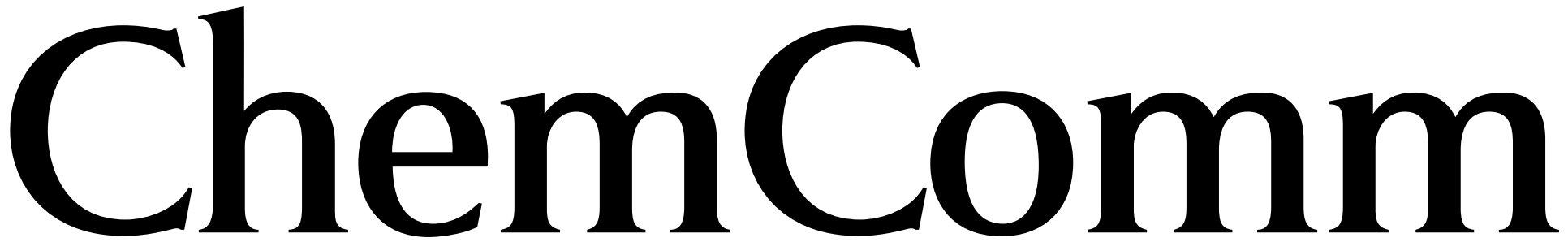

Chemical Communications

www.rsc.org/chemcomm

Volume 48 | Number 29 | 11 April 2012 | Pages 3465-3564

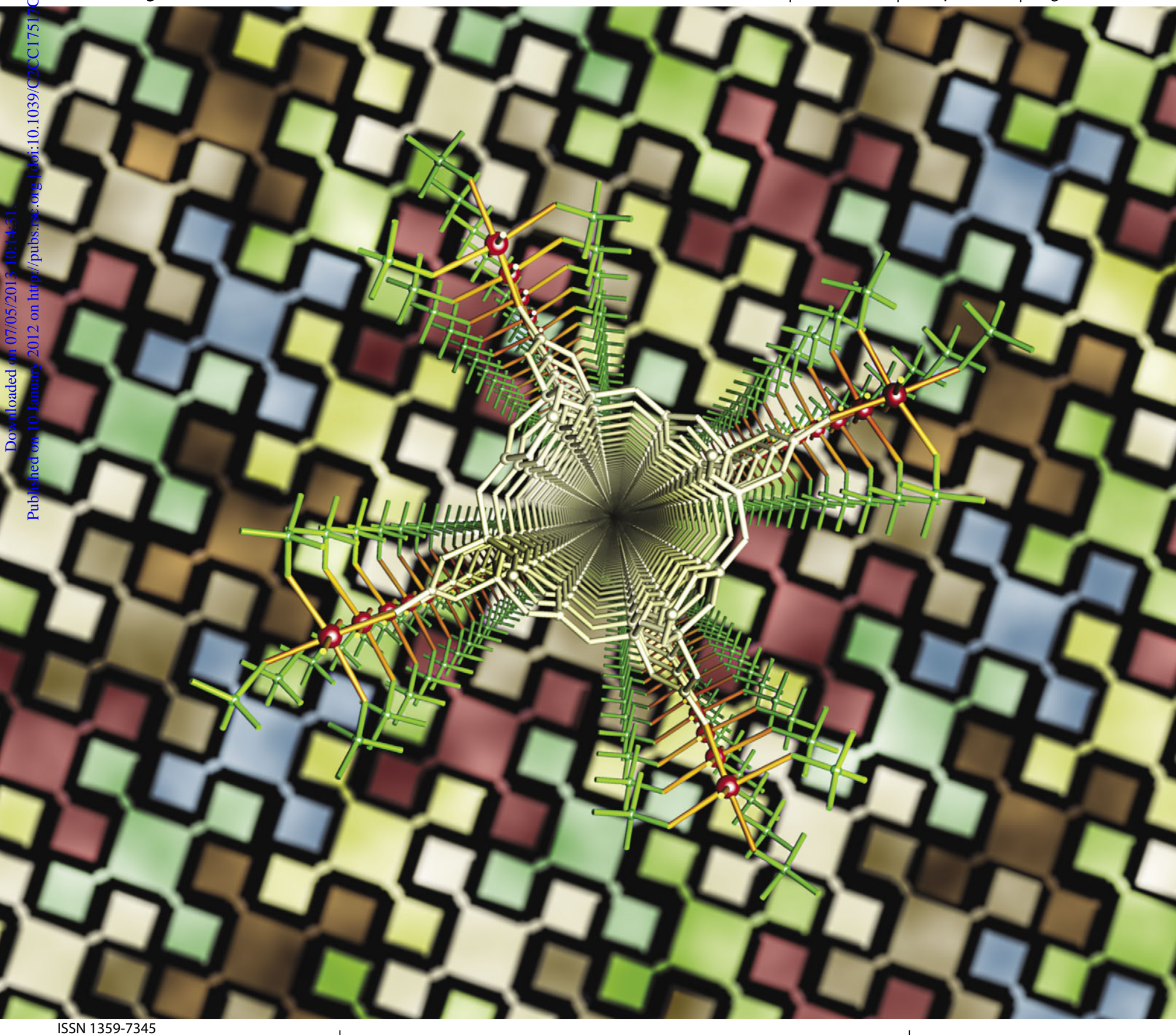




\title{
Complex clover cross-sectioned nanotubules exist in the structure of the first uranium borate phosphate $\dagger$
}

\author{
Shijun Wu, ${ }^{a b}$ Shuao Wang, ${ }^{c}$ Juan Diwu, ${ }^{c}$ Wulf Depmeier, ${ }^{a}$ Thomas Malcherek, ${ }^{d}$ \\ Evgeny V. Alekseev*e and Thomas E. Albrecht-Schmitt*c
}

Received 1st December 2011, Accepted 6th January 2012

DOI: $10.1039 / \mathrm{c} 2 \mathrm{cc17517g}$

An actinide borate phosphate was prepared via a high temperature solid-state reaction. This phase exhibits unprecedented complex inorganic nanotubular fragments with an external diameter of $\sim 2 \times 2 \mathrm{~nm}$. The nanotubular aggregates are based on borate tubes where the exterior of the tubes is decorated with $\mathrm{UO}_{2}\left(\mathrm{PO}_{4}\right)_{3}$ moieties to form a complex shape with a cross-section similar to the clover cross.

Nanostructured phases have been the focus of considerable interest since the discovery of carbon nanotubes. ${ }^{1}$ Numerous different topologies with nano-scale features have been found in the past two decades: nanotubes, nanorods, nanospheres, etc. Nanotubes are especially interesting owing to their unique chemical and physical properties. ${ }^{2}$ Most of these phases are not periodically ordered and are present in forms of fully or partially disordered arrays. Novel crystalline materials based on nanotubular fragments were observed recently in metalorganic hybrid materials and purely inorganic compounds. ${ }^{3}$ The family of inorganic phases based on nanotubular fragments is relatively small. It includes $\mathrm{Na}_{2} \mathrm{~V}_{3} \mathrm{O}_{7},{ }^{3 d} \mathrm{~K}_{5}\left[\left(\mathrm{UO}_{2}\right)_{3}\right.$ $\left.\left(\mathrm{SeO}_{4}\right)_{5}\right]\left(\mathrm{NO}_{3}\right)\left(\mathrm{H}_{2} \mathrm{O}\right)_{3.5},{ }^{3 e} \mathrm{SbPS}_{4},{ }^{3 f}$ and $\mathrm{Na}_{2} \mathrm{EuSiSe}_{4}{ }^{3 g}$ In addition, two organically-templated hybrid phases were reported with the following compositions: $\left(\mathrm{C}_{4} \mathrm{H}_{12} \mathrm{~N}\right)_{14}\left[\left(\mathrm{UO}_{2}\right)_{10}\left(\mathrm{SeO}_{4}\right)_{17}\left(\mathrm{H}_{2} \mathrm{O}\right)\right]^{3 h}$ and $\left(\mathrm{H}_{3} \mathrm{O}\right)_{2} \mathrm{~K}\left[\left(\mathrm{H}_{3} \mathrm{O}\right) @\left([18]\right.\right.$ crown-6)][( $\left.\left(\mathrm{UO}_{2}\right)_{3}\left(\mathrm{SeO}_{4}\right)_{5}\right]\left(\mathrm{H}_{2} \mathrm{O}\right)_{4}{ }^{3 i}{ }^{3 i}$ The nanotubules in the aforementioned phases possess classical tubular shapes with spherical, elliptical, or square-like cross-sections. The outer diameter of the tubes varies from 1 to $3.5 \mathrm{~nm}$ with internal dimensions from 0.5 to $1.5 \mathrm{~nm}$. In an attempt to synthesize

\footnotetext{
${ }^{a}$ Department of Crystallography, University of Kiel, $24118 \mathrm{Kiel}$, Germany

${ }^{b}$ Guangzhou Institute of Geochemistry, Chinese Academy of Sciences, 510640 Guangzhou, China

'Department of Civil Engineering and Geological Sciences and Department of Chemistry and Biochemistry, 156 Fitzpatrick Hall, University of Notre Dame, Notre Dame, Indiana 46556, USA. E-mail: talbrec1@nd.edu

${ }^{d}$ Mineralogisch-Petrographisches Institut, Universität Hamburg, 20146 Hamburg, Germany

${ }^{e}$ Forschungszentrum Jülich GmbH, Institute for Energy and Climate Research (IEK-6), 52428 Jülich, Germany.

E-mail: e.alekseev@fz-juelich.de

$\dagger$ Electronic supplementary information (ESI) available: CIF file for $\mathrm{Ba}_{5}\left[\left(\mathrm{UO}_{2}\right)\left(\mathrm{PO}_{4}\right)_{3}\left(\mathrm{~B}_{5} \mathrm{O}_{9}\right)\right]\left(\mathrm{H}_{2} \mathrm{O}\right)_{0.125}$. ICSD 423800 . For ESI and crystallographic data in CIF or other electronic format see DOI: 10.1039/ $\mathrm{c} 2 \mathrm{cc} 17517 \mathrm{~g}$
}

crystalline phases that might exist in vitrified nuclear waste, ${ }^{4}$ we synthesized a complex uranium(vI) borate phosphate, $\mathrm{Ba}_{5}\left[\left(\mathrm{UO}_{2}\right)\left(\mathrm{PO}_{4}\right)_{3}\left(\mathrm{~B}_{5} \mathrm{O}_{9}\right)\right] \cdot n \mathrm{H}_{2} \mathrm{O}(\mathbf{B a B P U 1}) \ddagger$ This compound has an unprecedented structure with nanotubular fragments. Borophosphates form a large group of inorganic phases with borate groups (triangles or tetrahedra) that are directly linked to $\mathrm{PO}_{4}$ groups. Borate phosphates are rather rare, and contain isolated borate and phosphate groups. ${ }^{5}$ There are no known actinide borophosphates or borate phosphates.

Crystals of BaBPU1 were obtained from a high-temperature solid-state reaction, and characterized by X-ray diffraction and by several spectroscopic methods. A view of the BaBPU1 crystal structure is shown in Fig. 1a.

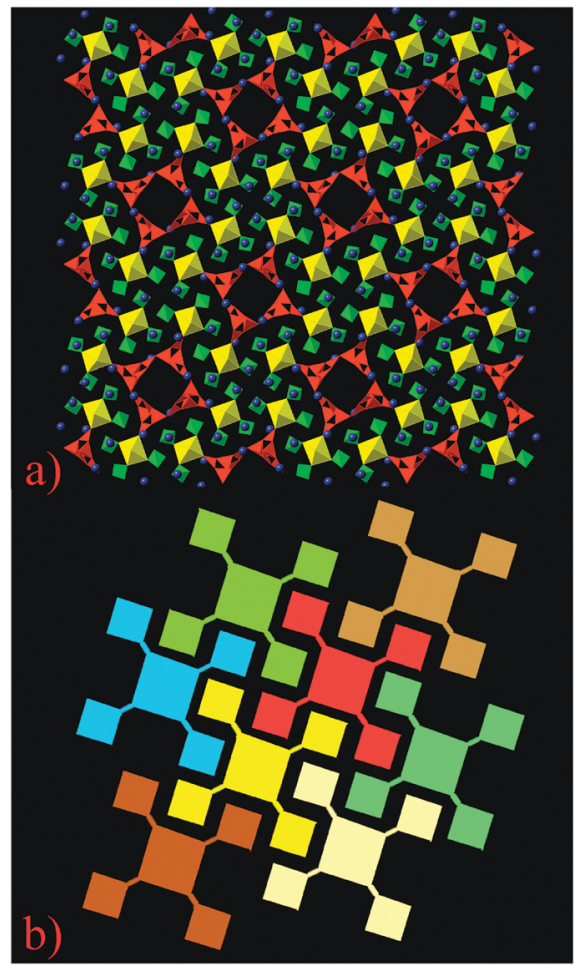

Fig. 1 View of BaBPU1 (a) and its schematic representation (see the text for details) (b). U polyhedra are shown in yellow, phosphate tetrahedra are shown in green, borate groups in red and $\mathrm{Ba}$ atoms are in blue (the color scheme refers to parts (a) and (b) only). Projection on (001). 

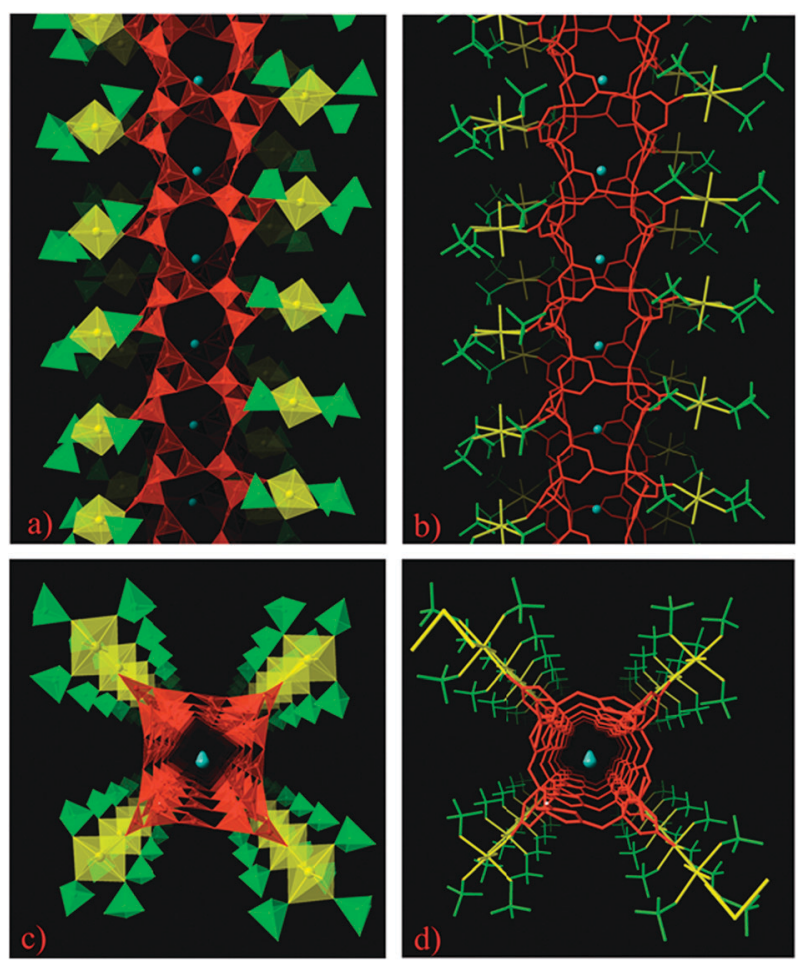

Fig. 2 The structure of nanotubules in BaBPU1. The polyhedral and skeletal view of side ( $a$ and $b$ ) and top projections (c and d). Colours are the same with those in Fig. 1, water molecules are light-blue.

The structure of BaBPU1 is based on complex nanotubular fragments with the composition of $\left[\left(\mathrm{UO}_{2}\right)\left(\mathrm{PO}_{4}\right)_{3}\left(\mathrm{~B}_{5} \mathrm{O}_{9}\right)\right]_{1 \infty}-$ linked by $\mathrm{Ba}^{2+}$ cations into a quasi $3 \mathrm{D}$ structure. The nanotubes have a complex shape that can be described as having a four-leafed clover cross-section. The external dimensions of the nanotubules are $\sim 2 \times 2 \mathrm{~nm}$, with an internal size approximately $\sim 0.6 \times 0.6 \mathrm{~nm}$ (measured from atom centers). Two main fragments can be separated within the structure of the nanotubules in BaBPU1. The first is a borate tubular porous net (shown in red in Fig. 2). The borate net is based on the pentaborate $\left[\mathrm{B}_{5} \mathrm{O}_{11}\right]$ anion, which can be viewed as a fundamental building block (FBB). The FBBs are linked via corner-sharing into polymeric tubules with a complex topology. The borate tubes have an external size of $1 \times 1 \mathrm{~nm}$. Water molecules occupy positions within the borate tube channels. The internal diameter is large enough to absorb water molecules directly from the air under standard conditions. The tubes are open from the sides and have nine-membered windows with an approximate size of $5 \times 6.5 \AA$. The $\mathrm{Ba}^{2+}$ cations reside in the pores. A skeletal view demonstrates that the topology of the nanotubules body in BaBPU1 is similar to those found in organic and metal-organic nanotubular phases with side pores. $^{3 a, b}$ Other inorganic nanotubes do not have pores on the sides. The borate nanotubular fragment in BaBPU1 is the only known example from borate chemistry to date.

The second fragment of this complex nanotubule is the $\mathrm{UO}_{2}\left(\mathrm{PO}_{4}\right)_{3}$ cluster $\left(\mathrm{UO}_{6}\right.$ shown in yellow and $\mathrm{PO}_{4}$ in green in Fig. 2). This fragment is quite well-known in uranyl phosphate chemistry and is based on almost linear uranyl groups corner-shared with $\mathrm{PO}_{4}$ tetrahedra. The uranyl groups are surrounded by only phosphate tetrahedra in all known

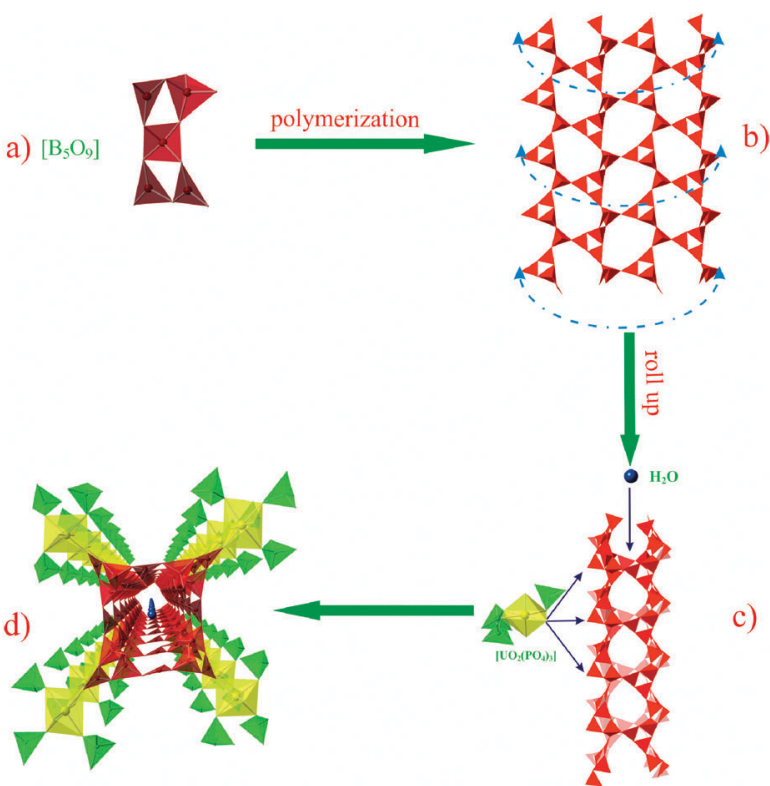

Fig. 3 A schematic representation of fragments hierarchy in BaBPU1 nanotubules.

uranyl phosphate-based materials. However, in BaBPU1, the fourth $\mathrm{PO}_{4}$ group is substituted by one $\mathrm{BO}_{3}$ triangle from the polyborate tubules.

The $\mathrm{U}=\mathrm{O}$ bond distances in the uranyl groups are approximately $1.812(4) \AA$, whereas the equatorial bonds range from $2.159(44) \AA$ to $2.322(4) \AA$. The U-O bond to the coordinating oxygen atom from the $\mathrm{BO}_{3}$ triangle has the shortest distance of 2.159(4) $\AA$. The bonds in the $\mathrm{PO}_{4}$ and $\mathrm{BO}_{4}$ tetrahedra are in the ranges of 1.511(4)-1.581(4) $\AA$ and 1.414(8)-1.497(8) $\AA$, respectively. The bonds in $\mathrm{BO}_{3}$ triangles are shorter and occur from $1.323(8)-1.395(8) \AA$.

The formation of the nanotubular fragment in BaBPU1 from simple groups to a complex aggregate is schematically shown in Fig. 3. The FBBs of polyborate nanotubes are $\left[\mathrm{B}_{5} \mathrm{O}_{11}\right]$ pentamers shown in Fig. 3a. This fragment is based on three $\mathrm{BO}_{3}$ triangles corner-linked with two $\mathrm{BO}_{4}$ tetrahedra, and can be described as $3 \Delta 2 \square:\langle\Delta 2 \square\rangle-\langle 2 \Delta \square\rangle$ according to the borate classification system. ${ }^{6}$ Corner-sharing polymerization of such groups gives a hypothetical 2D sheet with the structure shown in Fig. 3b. The layer has nine-membered holes similar to those we observed in recently described actinide borates. ${ }^{4}$ The sheet topology has been known in borate chemistry for natural biringuccite and several synthetic compounds. ${ }^{7}$ The process of converting layers into tubes can be described as simple rolling up. A similar process was described for vanadate nanotubes and was proposed for several other inorganic nanotubular materials. ${ }^{3,8}$ The resulting borate nanotubules (Fig. 3d) are surrounded by $\mathrm{UO}_{2}\left(\mathrm{PO}_{4}\right)_{3}$ groups via their interaction with the external $\mathrm{BO}_{3}$ triangles (Fig. 3c). Those $\mathrm{UO}_{2}\left(\mathrm{PO}_{4}\right)_{3}$ clusters facing each other (the angle between them is $180^{\circ}$ ) are shifted by $\frac{1}{2} c$ in a relation to the neighbouring groups $\left(90^{\circ}\right)$. This shift results in a stepwise shape. The resulting nanotubes have a complex shape with a cut similar to the clover (Celtic) cross.

We suggest that water molecules residing inside the tubes are absorbed from air during cooling. This is based on the 
synthetic method we used (the temperature of the synthesis was $1000^{\circ} \mathrm{C}$ ). It is obvious that water is driven off at such high temperatures and the only way for it to enter the nanotubes is water absorption after or during the process of crystal cooling. ${ }^{9}$ The water molecules occupy half of their positions inside the tubes. They are strongly distorted because the internal diameter of the nanotubes is slightly larger than the size of $\mathrm{H}_{2} \mathrm{O}$ molecules. The presence of water in molecular form was confirmed by absorptions near $1600 \mathrm{~cm}^{-1}$ and $3500 \mathrm{~cm}^{-1}$ in the IR spectrum.

The packing mode of these complex nanotubes in the structure of BaBPU1 is unusual (Fig. 1a and b). Normally, nanotubular fragments are packed in crystal structures with hexagonal or tetragonal packing. Such simple packing is impossible in BaBPU1 because of the cross-like forms of the $\mathrm{UO}_{2}\left(\mathrm{PO}_{4}\right)_{3}$ groups attached to the borate-based nanotubes. Generally, one can name the packing mode in BaBPU1 as a 3D puzzle assemblage. A schematic projection of nanotubes packing is shown in Fig. $1 \mathrm{~b}$ (borate nanotubes and $\mathrm{UO}_{2}\left(\mathrm{PO}_{4}\right)_{3}$ are shown in the form of large and small squares, respectively). Each $\mathrm{UO}_{2}\left(\mathrm{PO}_{4}\right)_{3}$ group from a single nanotube is inserted into the free space between the $\mathrm{UO}_{2}\left(\mathrm{PO}_{4}\right)_{3}$ groups of neighbouring nanotubes (for example yellow to red). The identical group from a third nanotube (cream colored) locks with the yellow $\mathrm{UO}_{2}\left(\mathrm{PO}_{4}\right)_{3}$ unit by inserting into the free space of the yellow nanotube. Simultaneously, the yellow $\mathrm{UO}_{2}\left(\mathrm{PO}_{4}\right)_{3}$ groups are locking the red ones by insertion into the free space of the pale greenish nanotube (Fig. 3c). All other nanotubes are locked in the same manner and form a zipper-like structure. Thus, the structure is stabilized not only by $\mathrm{Ba}^{2+}$ cations but also via coupling of the cross-shaped nanotubes. This makes the structure of BaBPU1 unique in the class of nanotubular based compounds.

This work was supported by Deutsche Forschungsgemeinschaft within the DE 412/43-1 and the Chemical Sciences, Geosciences, and Biosciences Division, Office of Basic Energy Sciences, Office of Science, Heavy Elements Program, U.S. Department of Energy, under Grant DE-SC0002215.

\section{Notes and references}

$\ddagger$ Synthesis: the crystals of $\mathrm{Ba}_{5}\left[\left(\mathrm{UO}_{2}\right)\left(\mathrm{PO}_{4}\right)_{3}\left(\mathrm{~B}_{5} \mathrm{O}_{9}\right)\right]\left(\mathrm{H}_{2} \mathrm{O}\right)_{0.125}$ were obtained from a high-temperature solid state reaction. The following compounds were used as initial components: $\mathrm{H}_{3} \mathrm{BO}_{3}(61.38 \mathrm{mg}) ; \mathrm{BPO}_{4}$ $(52.89 \mathrm{mg}) ; \mathrm{UO}_{2}\left(\mathrm{NO}_{3}\right)_{2} \cdot 6 \mathrm{H}_{2} \mathrm{O}(251.05 \mathrm{mg}) ; \mathrm{Ba}\left(\mathrm{CO}_{3}\right)_{2}(197.34 \mathrm{mg})$. The components were ground in an agate mortar, placed into a platinum crucible, heated to $1000{ }^{\circ} \mathrm{C}$ and then slowly $\left(5^{\circ} \mathrm{C} \mathrm{h}^{-1}\right)$ cooled to the room temperature. The resulting mixture consisted of BaBPU1 crystals (estimated yield $8-10 \%$ ) and a glassy mass. Crystallographic data for $\mathrm{Ba}_{5}\left[\left(\mathrm{UO}_{2}\right)\left(\mathrm{PO}_{4}\right)_{3}\left(\mathrm{~B}_{5} \mathrm{O}_{9}\right)\right]\left(\mathrm{H}_{2} \mathrm{O}\right)_{0.125}$ : green needle, $0.28 \times 0.09 \times 0.08 \mathrm{~mm}$, tetragonal, $M_{\mathrm{r}}=1441.89, P 4_{2} / n, Z=8, a=b=24.934(4) \AA, c=$ $6.7732(6) \AA, V=4211.0(9) \AA^{3}(T=293(2) \mathrm{K}), \mu=172.05 \mathrm{~cm}^{-1}, N_{\text {Ref }}=$ $55046 / 4643, R_{\text {int }}=0.139, R_{1}=0.0254$ for $F_{\mathrm{o}}{ }^{2}>2 \sigma\left(F_{\mathrm{o}}{ }^{2}\right), \mathrm{w} R_{2}=0.0437$ for all data. Infrared spectra of BaBPU1 exhibit strong absorption bands at 1320 and $1280 \mathrm{~cm}^{-1}$ which can be assigned to $\nu_{\text {as }}$ of $\mathrm{BO}_{4}$ and $\mathrm{BO}_{3}$ groups. The $\nu_{\mathrm{s}}$ of $\mathrm{BO}_{4}$ and $\mathrm{BO}_{3}$ groups are in the range $600-810 \mathrm{~cm}^{-1}$. The vibrations of $\mathrm{UO}_{2}{ }^{2+}$ groups are in the range from 848 to $966 \mathrm{~cm}^{-1}$. The bands of $\mathrm{PO}_{4}$ are in the range $1000-1066 \mathrm{~cm}^{-1}$. The presence of water is confirmed by the bands at 1633 and $3474 \mathrm{~cm}^{-1}$. The UV-vis-NIR and fluorescence spectra of BaBPU1 are also typical for the presence of $\mathrm{UO}_{2}{ }^{2+}$ (see ESI $\dagger$ ).

1 S. Iijima, Nature, 1991, 354, 56-58.

2 (a) R. H. Baughman, A. A. Zakhidov and W. A. De Heer, Science, 2002, 297, 787-792; (b) P. Roy, S. Berger and P. Schmuki, Angew. Chem., Int. Ed., 2011, 50, 2904-2939.

3 (a) T.-T. Luo, H.-C. Wu, Y.-C. Jao, S.-M. Huang, T.-W. Tseng, Y.-S. Wen, G.-H. Lee, S.-M. Peng and K.-L. Lu, Angew. Chem., Int. Ed., 2009, 48, 9461-9464; (b) K. Otsubo, Y. Wakabayashi, J. Ohara, S. Yamamoto, H. Matsuzaki, H. Okamoto, K. Nitta, T. Uruga and H. Kitagawa, Nat. Mater., 2011, 10, 291-295; (c) P. Thanasekaran, T.-T. Luo, C.-H. Lee and K.-L. Lu, J. Mater. Chem., 2011, 21, 13140-13149; (d) P. Millet, J. Y. Henry, F. Mila and J. Galy, J. Solid State Chem., 1999, 147, 676-678; (e) S. V. Krivovichev, V. Kahlenberg, R. Kaindl, E. Mersdorf, I. G. Tananaev and B. F. Myasoedov, Angew. Chem., Int. Ed., 2005, 44, 1134-1136; (f) C. D. Malliakas and M. G. Kanatzidis, J. Am. Chem. Soc., 2006, 128, 6538-6539; $(g)$ A. Choudhury and P. K. Dorhout, J. Am. Chem. Soc., 2007, 129, 9270-9271; (h) S. V. Krivovichev, V. Kahlenberg, I. G. Tananaev, R. Kaindl, E. Mersdorf and B. F. Myasoedov, J. Am. Chem. Soc., 2005, 127, 1072-1073; (i) E. V. Alekseev, S. V. Krivovichev and W. Depmeier, Angew. Chem., Int. Ed., 2008, 47, 549-551.

4 (a) S. Wang, E. V. Alekseev, J. Diwu, W. H. Casey, B. L. Phillips, W. Depmeier and T. E. Albrecht-Schmitt, Angew. Chem., Int. Ed., 2010, 49, 1057-1060; (b) P. Yu, S. Wang, E. V. Alekseev, W. Depmeier, T. E. Albrecht-Schmitt, B. Phillips and W. Casey, Angew. Chem., Int. Ed., 2010, 49, 5975-5977; (c) S. Wang, E. V. Alekseev, J. Ling, G. Liu, W. Depmeier and T. E. AlbrechtSchmitt, Chem. Mater., 2010, 22, 2155-2163; (d) S. Wang, E. V. Alekseev, J. T. Stritzinger, W. Depmeier and T. E. Albrecht-Schmitt, Inorg. Chem., 2010, 49, 2948-2953; (e) S. Wang, E. V. Alekseev, J. T. Stritzinger, W. Depmeier and T. E. Albrecht-Schmitt, Inorg. Chem., 2010, 49, 6690-6696; (f) S. Wang, E. V. Alekseev, J. T. Stritzinger, G. Liu, W. Depmeier and T. E. Albrecht-Schmitt, Chem. Mater., 2010, 22, 5983-5991; (g) S. Wang, E. V. Alekseev, J. Ling, S. Skanthakumar, L. Soderholm, W. Depmeier and T. E. Albrecht-Schmitt, Angew. Chem., Int. Ed., 2010, 49, 1263-1266; $(h)$ S. Wang, E. V. Alekseev, W. Depmeier and T. E. Albrecht-Schmitt, Chem. Commun., 2010, 46, 3955-3957; (i) S. Wang, E. V. Alekseev, H. M. Miller, W. Depmeier and T. E. Albrecht-Schmitt, Inorg. Chem., 2010, 49, 9755-9757; (j) S. Wang, E. M. Villa, J. Diwu, E. V. Alekseev, W. Depmeier and T. E. Albrecht-Schmitt, Inorg. Chem., 2011, 50, 2527-2533; (k) S. Wang, E. V. Alekseev, W. Depmeier and T. E. AlbrechtSchmitt, Inorg. Chem., 2011, 50, 2079-2081; (l) S. Wang, E. V. Alekseev, J. Diwu, H. M. Miller, A. Oliver, G. Liu, W. Depmeier and T. E. Albrecht-Schmitt, Chem. Mater., 2011, 23, 2931-2939; (m) M. J. Polinski, S. Wang, E. V. Alekseev, W. Depmeier and T. E. Albrecht-Schmitt, Angew. Chem., Int. Ed., 2011, 50, 8891-8894.

5 B. Ewald, Y.-X. Huang and R. Kniep, Z. Anorg. Allg. Chem., 2007, 633, $1517-1540$.

6 P. C. Burns, J. D. Grice and F. C. Hawthorne, Can. Mineral., 1995, 33, 1131-1151.

7 (a) E. Corazza, S. Menchetti and C. Sabelli, Am. Mineral., 1974, 59, 1005-1015; (b) P. M. Gasperin, Acta Crystallogr., Sect. C: Cryst. Struct. Commun., 1987, C43, 2031-2033; (c) P. M. Gasperin, Acta Crystallogr., Sect. C: Cryst. Struct. Commun., 1987, C43, $2264-2266$.

8 (a) K. S. Pillai, F. Krumeich, H.-J. Muhr, M. Niederberger and R. Nesper, Solid State Ionics, 2001, 141-142, 185-190; (b) Y. D. Li, X. L. Li, R. R. He, J. Zhu and Z. X. Deng, J. Am. Chem. Soc., 2002, 124, 1411; (c) C. Ye, G. Meng, Z. Jiang, Y. Wang, G. Wang and L. Zhang, J. Am. Chem. Soc., 2002, 124, 15180-15181.

9 E. V. Alekseev, S. V. Krivovichev and W. Depmeier, J. Solid State Chem., 2009, 182, 2074-2080. 